hexagonal rings that then assemble into a tube. When the temperature rises or falls, the segments slide against each other and the tubule expands or contracts, undergoing extensive structural changes but maintaining its hollow arrangement.

Science 337, 1521-1526 (2012)

\section{MICROBIAL ECOLOGY}

\section{Symbiosis may fertilize seas}

An unusual partnership between single-celled algae and cyanobacteria may provide a key source of nitrogen for marine life, and could shed light on how plants evolved to have photosynthetic organelles.

Jonathan Zehr at the University of California, Santa Cruz, and his colleagues investigated a widespread

¿ cyanobacterium that lacks certain genes involved in photosynthesis and metabolism but can convert atmospheric nitrogen into forms that other organisms can use. Zehr and his team sampled sea water (pictured) to look for symbiotic partners of the bacterium, and found a kind of unicellular alga. The bacterium attaches to the cell wall of the alga, and provides it with nitrogen in exchange for carbon.

The symbiosis is probably crucial to global carbon and nitrogen cycles, and is analogous to the early stages of an evolutionary process in which plants acquired microbes that would eventually become chloroplasts, the organelles that perform photosynthesis. Science 337, 1546-1550 (2012)

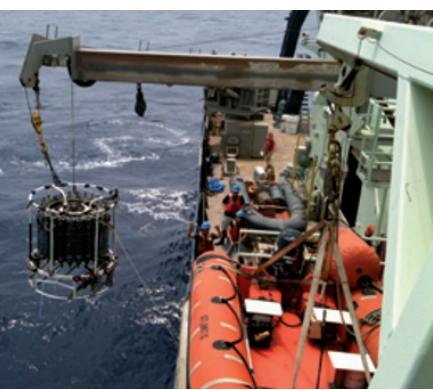

CLIMATE CHANGE

\section{Arctic snow lost faster than ice}

The rate of loss of Arctic snow cover during spring is outpacing even the rapid decline of sea ice.

Chris Derksen in Toronto and Ross Brown in Montreal, both of Environment Canada, looked at satellite data on high-latitude snow cover between April and June since 1979 , and compared it with observed changes in the extent of Arctic sea ice in the same period. In most Arctic land areas, snow cover remaining in June had decreased by almost $20 \%$ per decade. Arctic sea ice, which this summer melted to a new record low, has declined by about $10 \%$ per decade since 1979.

State-of-the-art climate models have considerably underestimated the accelerating downward trend in both snow cover and sea-ice extent since 2005, the authors note.

Geophys. Res. Lett. http://dx.doi. org/10.1029/2012GL053387 (2012)

\section{DEVELOPMENTAL BIOLOGY}

\section{Salamanders heal like embryos grow}

The Mexican axolotl salamander, known for its ability to regrow lost limbs, may heal by reprogramming cells in the stumps of the amputated limbs to mimic developing embryonic cells.

Tony Hunter at the Salk Institute for Biological Studies in La Jolla, California, and his colleagues found that limb amputation in the axolotl (Ambystoma mexicanum, pictured) triggered expression of two genes, PL1 and PL2 - which are active in sperm and egg cells and in developing embryos - in the new outgrowth. The same genes were not stimulated near superficial wounds. Suppressing production of the PL1 and PL2 proteins

COMMUNITY CHOICE

The most viewed papers in science

\title{
A peek at organelles in live cells
}

\section{HIGHLY READ \\ on www.pnas.org in August}

Small molecules can be used for highresolution fluorescence imaging of membrane-bound organelles in living cells. A team led by Guo-Qiang Bi at the University of Science and Technology of China in Hefei and Xiaowei Zhuang at Harvard University in Cambridge, Massachusetts, developed a fluorescence-imaging method that uses common membrane probes. The researchers showed that the fluorescence of eight such probes can be switched on and off in living cells in normal culture medium, enabling high-resolution imaging. Using the probes, the researchers were able to obtain images of key organelles, including the power-generating mitochondria, with a spatial resolution of 30-60 nanometres and a temporal resolution of 1-2 seconds. This allowed them to capture previously unseen details about the dynamic membranes of the organelles, such as structures involved in the fusing of mitochondria.

Proc. Natl Acad. Sci. USA 109, 13978-13983 (2012)

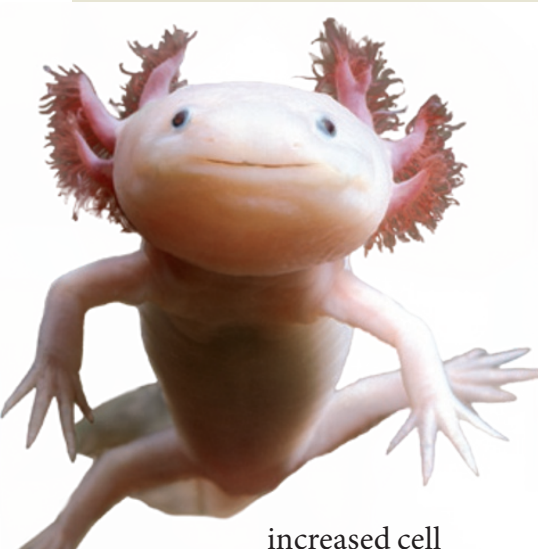

Hai Yan and his colleagues at Duke University in Durham, North Carolina, identified stretches of amino acids from oxidoreductase enzymes with cancerassociated mutations. These mutations change the chemical reaction that the enzymes carry out on their substrates, molecules with a backbone of five carbon atoms. The researchers introduced these amino-acid residues into the active sites of related enzymes that act on substrates containing six carbon atoms. The resulting enzyme performed the desired cancer-associated reaction on six-carbon molecules, and could catalyse a reaction in the synthesis of adipic acid, a precursor of nylon.

The authors suggest that data from sequenced cancer genomes could be used to increase functional diversity in enzymes.

Nature Chem. Biol. http://dx.doi. org/10.1038/nchembio.1065 (2012)

Mutations found in human cancer cells have been used to make enzymes that catalyse a reaction important in nylon production.

\section{SNATURE.COM}

For the latest research published by Naturevisit:

www.nature.com/latestresearch 